\title{
Convenient access to pyrrolidin-3-ylphosphonic acids and tetrahydro-2H-pyran-3-ylphosphonates with multiple contiguous stereocenters from nonracemic adducts of a $\mathrm{Ni}$ (II)-catalyzed Michael reaction
}

\author{
Alexander N. Reznikov ${ }^{*}$, Dmitry S. Nikerov ${ }^{1}$, Anastasiya E. Sibiryakova ${ }^{1}$, \\ Victor B. Rybakov ${ }^{2}$, Evgeniy V. Golovin ${ }^{1}$ and Yuri N. Klimochkin ${ }^{1}$
}

\section{Full Research Paper}

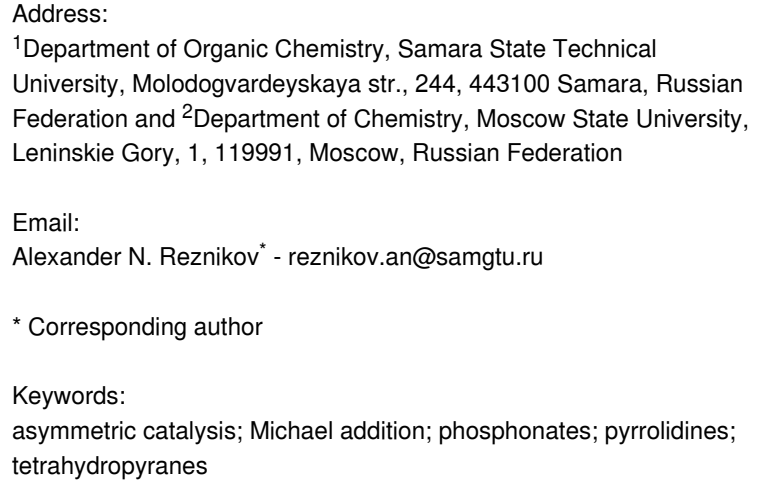

${ }^{1}$ Department of Organic Chemistry, Samara State Technical University, Molodogvardeyskaya str., 244, 443100 Samara, Russian Federation and ${ }^{2}$ Department of Chemistry, Moscow State University, Leninskie Gory, 1, 119991, Moscow, Russian Federation

\author{
Beilstein J. Org. Chem. 2020, 16, 2073-2079. \\ https://doi.org/10.3762/bjoc. 16.174 \\ Received: 15 May 2020 \\ Accepted: 10 August 2020 \\ Published: 25 August 2020 \\ Associate Editor: K. Grela \\ (C) 2020 Reznikov et al.; licensee Beilstein-Institut. \\ License and terms: see end of document.
}

\begin{abstract}
A new synthetic strategy toward nonracemic phosphoryl-substituted pyrrolidines and tetrahydropyranes with three and five contiguous stereocenters is presented. Readily available $\beta$-keto phosphonates react with conjugated nitroolefins in the presence of a chiral Ni(II) complex to give nitro keto phosphonates with two stereocenters with excellent enantioselectivity and moderate to high diastereoselectivity. These products were used for a reductive cyclization leading to pyrrolidin-3-ylphosphonic acid and for reactions with aldehydes yielding tetrahydropyranylphosphonates as individual stereoisomers. These nonracemic heterocycles containing phosphoryl moieties are useful for designing new pharmacologically active compounds.
\end{abstract}

\section{Introduction}

Chiral phosphonates [1,2] and phosphoryl-substituted heterocycles [2-4] have received significant attention in recent years due to their wide range of biological activity. For example, SF-2312 (1) is a natural antibiotic - an enolase inhibitor produced by the actinomycete Micromonospora [5]. Dipeptide analogs with phosphonoproline $\mathbf{2}$ and piperidine-2-phosphonic acid 3 are potent inhibitors of dipeptidyl peptidase IV [6,7].
Oxygen-containing heterocycles containing a phosphoryl group are also of interest in the development of new drugs. It is known that phosphorylated carbohydrate analogues $\mathbf{4}$ and $\mathbf{5}$ are neuraminidase inhibitors (Figure 1) [8,9].

These circumstances create an interest in discovering synthetic routes for obtaining nonracemic phosphoryl-substituted hetero- 
<smiles>O=C1C(=O)N(O)C(O)C1CC[AsH2+]</smiles>

(enolase inhibitor)<smiles>CC(N)C(=O)N1CCCCC1P(=O)(Oc1ccccc1)Oc1ccc(Cl)cc1</smiles><smiles>N=C(N)N[C@H]1C=C(P(=O)(O)O)O[C@@H]([C@H](O)[C@H](O)CO)[C@@H]1N</smiles>

4

phosphono-zanamivir neuraminidaze inhibitor

Figure 1: Pharmacologically active nonracemic phosphonates with heterocyclic moieties.

cycles. Thus, in recent years, effective methods for the asymmetric synthesis of chiral phosphonates containing octahydroindole [10], tetrahydroquinoline [11], tetrahydroisoquinoline [11,12], $\beta$-carboline [13], morpholine [14], and isoindoline [15] moieties have been developed. Obtained in an enantiomerically pure form, phosphonoproline and its analogues [16-19] were among the first compounds in this series. Surprisingly, the methods for obtaining chiral pyrrolidin-3-ylphosphonic acids, tetrahydropyranylphosphonic acids and their esters have experienced minimal development [20-22]. The use of atom-efficient methods of asymmetric catalysis for the synthesis of such compounds is extremely relevant. The chiral metal-complexes-catalyzed [23-26] or organocatalyzed [27-32] Michael reaction is one of the most important synthetic tools for the asymmetric formation of a $\mathrm{C}-\mathrm{C}$ bond. Moreover, the generation of the first stereocenter of a given configuration during the catalytic process leads to the possibility of creating enantiomerically pure compounds with several stereocenters through the directed regulation of diastereoselectivity in subsequent transformations, which can be realized as stepwise or cascade processes. Due to this reason, the Michael reaction was successfully used over the last decade to synthesize a wide range of heterocycles [33-44] 2-Oxo-4-nitrophosphonates $[45,46]$, the Michael adducts of $\beta$-keto phosphonates and nitroolefins, can be considered as versatile reagents for the synthesis of various phosphoryl- substituted heterocycles. The present work reports on the synthesis of nonracemic phosphoryl-substituted pyrrolidines and tetrahydropyranes via Ni(II)-catalyzed asymmetric Michael addition of $\beta$-keto phosphonates to conjugated nitroolefins.

\section{Results and Discussion}

For the synthesis of nonracemic polysubstituted pyrrolidin-3ylphosphonic acids and tetrahydropyranylphosphonates, we assumed that the 4-nitro-2-oxophosphonates - the Michael adducts of $\beta$-keto phosphonates and nitroolefins - are suitable precursors, considering that the $\mathrm{Ni}(\mathrm{II})$-catalyzed Michael addition was carried out not only enantioselectively, but also diastereoselectively, such has been previously described [45]. These considerations prompted us to explore further applications of 4-nitro-2-oxophosphonates containing two contiguous stereocenters for the synthesis of the target compounds. Initially, 4-nitro-2-oxophosphonates 6a-f (Figure 2) were synthesized similar to the reported procedure $[45,46]$ from corresponding $\beta$-keto phosphonates and nitroolefins in the presence of $2 \mathrm{~mol} \%$ of the $\mathrm{Ni}(\mathrm{II})$ complex with dr 11:1 to $1: 0$ and $98->99 \%$ ee (see Supporting Information File 1).<smiles>COP(=O)(OC)[C@H](C(=O)c1ccccc1)[C@@H](CN=O)c1ccccc1</smiles>

$(2 R, 3 S)-6 a$ $45 \%$ yield dr 37:1 $>99 \%$ ee<smiles>COc1cccc(C(=O)[C@H](C[N+](=O)[O-])[C@H](C[N+](=O)[O-])c2ccccc2)c1</smiles>

$(2 R, 3 S)-6 \mathrm{c}$

$45 \%$ yield

dr 14:1

$>99 \%$ ee<smiles>COP(=O)(OC)[C@H](C(C)=O)[C@H](C[N+](=O)[O-])c1ccccc1</smiles>

(2S,3S)-6e $46 \%$ yield dr 11:1 $>99 \%$ ee<smiles>COc1ccc(C(=O)[C@H]([C@H](C[N+](=O)[O-])c2ccccc2)P(=O)(OC)OC)cc1</smiles>

$$
\begin{gathered}
(2 R, 3 S)-6 \mathbf{b} \\
46 \% \text { yield } \\
\text { dr } 1: 0 \\
98 \% \text { ee }
\end{gathered}
$$<smiles>COc1ccccc1C(=O)[C@@H]([C@H](C[N+](=O)[O-])c1ccccc1)P(=O)(OC)OC</smiles>

(2S,3S)-6d

$50 \%$ yield

dr 1:0

$98 \%$ ee<smiles></smiles>

(2S,3S)-6f

$21 \%$ yield

dr 25:1

$>99 \%$ ee
Figure 2: Starting nonracemic 4-nitro-2-oxophosphonates. 
A search for acceptable hydrogenation conditions was carried out using compound 6a. Hydrogenation in the presence of Raney nickel or $\mathrm{Pd} / \mathrm{C}$ in various solvents leads to a mixture of products, among which $\mathbf{8}$ and $\mathbf{9}$ are identified (Scheme 1).

A satisfactory yield of the desired product 7 (78\% by ${ }^{31} \mathrm{P}$ NMR of reaction mixture) was achieved when the hydrogenation was carried out in acetic acid in the presence of Pd/C. However, phosphonate 7 was unstable: already during its isolation, it was partially transformed into compounds 8 and $\mathbf{9}$. It can be assumed that $\mathrm{N}$-alkylation by the phosphoryl group occurs [4749].

To avoid this undesirable process, the product 7 was formylated before its isolation. The formylated product 10a may be purified by chromatography without decomposition. Subsequent acid hydrolysis of compound 10a leads to pyrrolidinylphosphonic acid hydrochloride 11a (Scheme 2).

Similarly, pyrrolidinylphosphonic acids $\mathbf{1 1 b}-\mathbf{d}$ were obtained from the corresponding phosphonates $\mathbf{6 b}, \mathbf{c}, \mathbf{e}$ (Scheme 2).
An X-ray diffraction study [50] of the formyl derivative 10a showed its $(2 R, 3 R, 4 S)$-configuration (Figure 3$)$. The absolute configuration of the other phosphonates $\mathbf{1 0 b}-\mathbf{d}$ and $\mathbf{1 1 b}-\mathbf{d}$ is assumed by analogy.

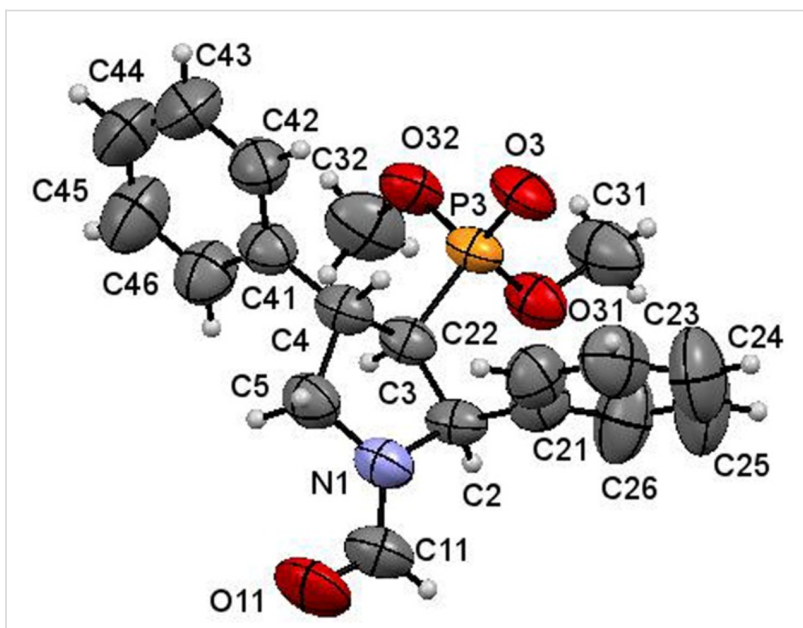

Figure 3: ORTEP diagram of $(2 R, 3 R, 4 S)-\mathbf{1 0 a}$.

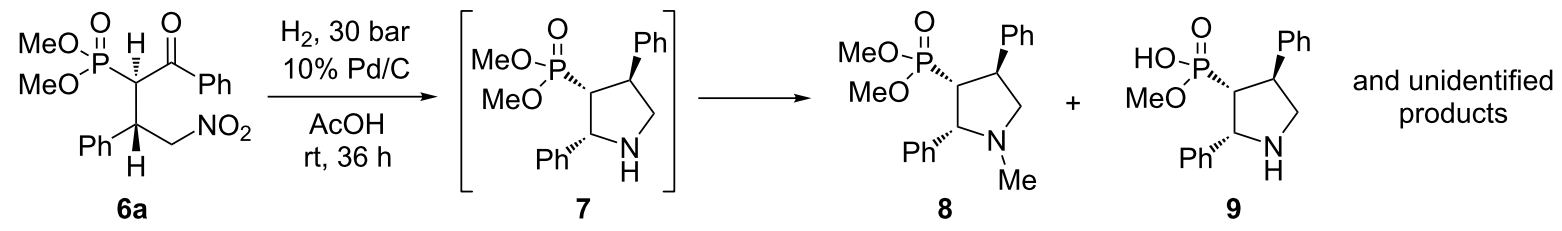

Scheme 1: Intermolecular N-methylation of reduction product 7.

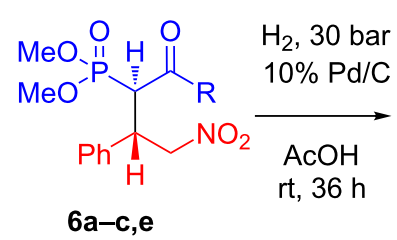

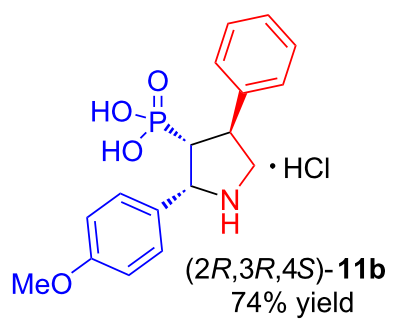

$74 \%$ yield

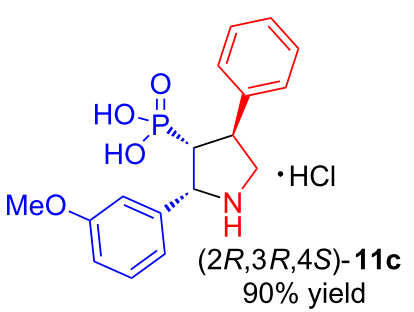

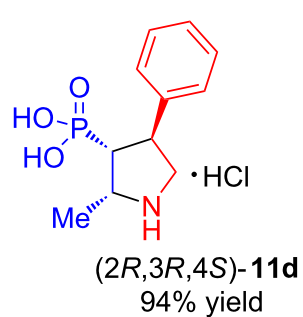


Hydrogenation of phosphonates $\mathbf{6 d , f}$ with $o$-anisyl and bulky adamantan-1-yl substituents at the carbonyl leads to a mixture of unidentified products.

At the next stage of this work, the Henry/acetalization reaction with phosphonate $\mathbf{6 e}$ was studied. To optimize the reaction conditions various bases and solvents were used. The reaction of phosphonate 6e with propionic aldehyde 12a was used as a model reaction (see Table 1).

Initially, the catalytic ability of organic bases was studied for the Henry/acetalyzation reaction by using $0.1-1.0$ equiv of catalyst in THF as a solvent. Unfortunately, no product formation was observed in the presence of $N, N$-dimethylaniline (Table 1 , entry 1) and unidentified products were formed when stronger bases such as triethylamine or DBU were used (Table 1, entries 2 and 3). Later on, inorganic bases in combination with a phase transfer agent such as benzyltriethylammonium chloride (TEBAC) were tried as catalysts for the same reaction. Similarly, no products were detected in the reaction even after $72 \mathrm{~h}$ in the presence of 1 equiv of potassium phosphate or carbonate with TEBAC ( 0.1 equiv, Table 1, entries 4 and 5). If potassium fluoride or cesium carbonate were used as a base, the initial phosphonate 6e was consumed in a few hours, but unidentified products were formed (Table 1, entries 6 and 7). After this, the reaction was carried out in an aqueous-organic medium. Fortunately, an individual diastereomer of Henry/acetalyzation product 13a was obtained when $\mathrm{K}_{2} \mathrm{CO}_{3}$ in combination with TEBAC was used as a catalyst. A THF/water ratio of 7.5:1 is important in order to get the best yield (Table 1, entry 9). Lower yields and dr values for compound 13a were obtained when 18-crown-6 was used as the phase-transfer catalyst (Table 1, entries 10-12).

With the optimized reaction conditions in hand, the transformation was studied with a series of phosphonates and aldehydes. As shown in Scheme 3, the reaction of phosphonate $\mathbf{6 e}$ gave moderate yields with various aliphatic and aromatic aldehydes 12a-f. The presence of a bulkier (compared to methyl) group at the carbonyl in the phosphonates $\mathbf{6 a - d , f}$ leads to no reaction.

Tetrahydropyranols 13a-f were obtained with good diastereomeric purity. In the ${ }^{1} \mathrm{H}$ NMR spectra of $\mathbf{1 3 a}-\mathbf{f}$ signals of methine groups with characteristic spin-spin coupling constants for axially located protons $(12.1,12.3$ and $12.5 \mathrm{~Hz})$ were observed.

The structure and absolute $(2 S, 3 R, 4 S, 5 S, 6 R)$-configuration of the tetrahydropyranol $\mathbf{1 3 b}$ have been confirmed by singlecrystal X-ray crystallographic analysis (Figure 4) [51].

Table 1: Optimization of the conditions of Henry/acetalyzation reaction with phosphonate $6 \mathrm{e}^{\mathrm{a}}$

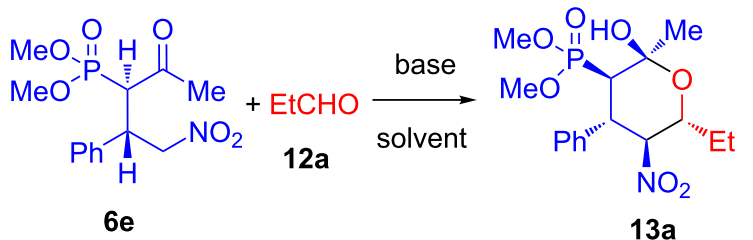

\begin{tabular}{|c|c|c|c|c|c|}
\hline Entry & Base & Phase transfer catalyst & Solvent & Yield of $\mathbf{1 3 a}(\%)$ & $d r^{b}$ \\
\hline 1 & $\mathrm{PhNMe}_{2}$ & - & THF & 0 & - \\
\hline 2 & $\mathrm{Et}_{3} \mathrm{~N}$ & - & THF & $0^{c}$ & - \\
\hline 3 & DBU & - & THF & $0^{c}$ & - \\
\hline 4 & $\mathrm{~K}_{3} \mathrm{PO}_{4}$ & TEBAC & THF & 0 & - \\
\hline 5 & $\mathrm{~K}_{2} \mathrm{CO}_{3}$ & TEBAC & THF & 0 & - \\
\hline 6 & $\mathrm{KF}$ & TEBAC & THF & $0^{c}$ & - \\
\hline 7 & $\mathrm{Cs}_{2} \mathrm{CO}_{3}$ & - & THF & $0^{c}$ & - \\
\hline 8 & $\mathrm{~K}_{2} \mathrm{CO}_{3}$ & TEBAC & $\mathrm{THF} / \mathrm{H}_{2} \mathrm{O} 1: 1$ & $0^{c}$ & - \\
\hline 9 & $\mathrm{~K}_{2} \mathrm{CO}_{3}$ & TEBAC & $\mathrm{THF} / \mathrm{H}_{2} \mathrm{O} 7.5: 1$ & 34 & $1: 0$ \\
\hline 10 & $\mathrm{~K}_{2} \mathrm{CO}_{3}$ & 18-crown-6 & $\mathrm{CH}_{3} \mathrm{CN}$ & 30 & $11: 1$ \\
\hline 11 & $\mathrm{~K}_{2} \mathrm{CO}_{3}$ & 18-crown-6 & THF & 17 & $16: 1$ \\
\hline 12 & $\mathrm{~K}_{2} \mathrm{CO}_{3}$ & 18-crown-6 & $\mathrm{CH}_{2} \mathrm{Cl}_{2}$ & 12 & $10: 1$ \\
\hline
\end{tabular}

${ }^{a}$ Reaction conditions: phosphonate $6 \mathrm{e}(1.58 \mathrm{mmol})$, aldehyde $12 \mathrm{a}(15.8 \mathrm{mmol})$, solvent $(17 \mathrm{~mL})$, base $(1.58 \mathrm{mmol})$, phase transfer catalyst $(0.158 \mathrm{mmol})$, rt, $72 \mathrm{~h}$; ${ }^{\mathrm{b}}$ determined by ${ }^{31} \mathrm{P}$ NMR; Cfull phosphonate $6 \mathrm{e}$ conversion was observed and unidentified products were formed. 

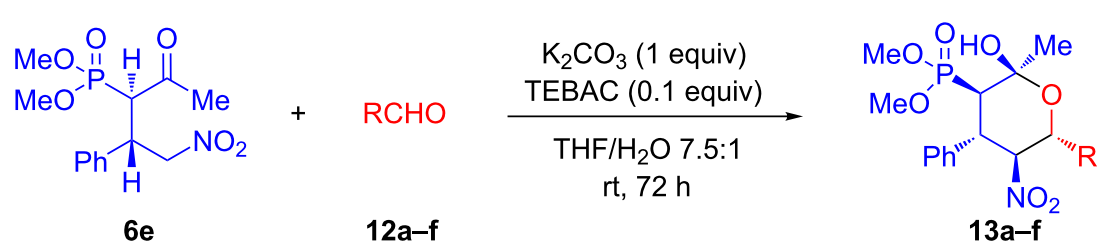

$6 e$

$12 a-f$<smiles>CCP[C@H]1O[C@@](C)(O)[C@@H](P(=O)(OC)OC)[C@H](c2ccccc2)[C@@H]1[N+](=O)[O-]</smiles>

$13 a$

$34 \%$ yield

dr 1:0<smiles>COP(=O)(OC)[C@H]1[C@H](c2ccccc2)[C@H](I)[C@@H](CBr)O[C@]1(C)O</smiles>

$13 d$

$30 \%$ yield

dr 9:1<smiles>CO[P+]([O-])(O)C1C([N+](=O)[O-])C([N+](=O)[O-])OC(C)(O)C1[N+](=O)[O-]</smiles>

$13 \mathrm{~b}$

$36 \%$ yield

dr 14:1

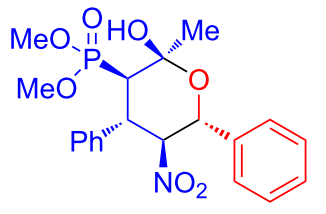

$13 e$

$32 \%$ yield

dr $1: 0$
$13 \mathrm{c}$

$35 \%$ yield

dr 10:1

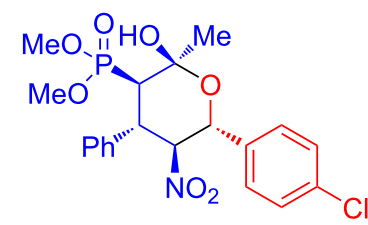

$13 f$

$30 \%$ yield

dr 1:0

Scheme 3: Synthesis of tetrahydropyranylphosphonates $13 a-f$ via diastereoselective Henry/acetalyzation reaction.

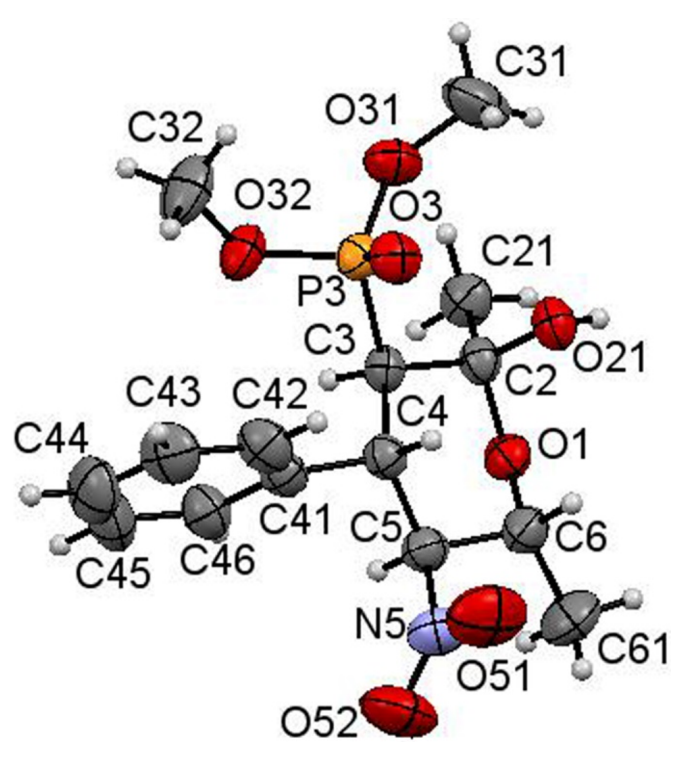

Figure 4: ORTEP diagram of $(2 S, 3 R, 4 S, 5 S, 6 R)-\mathbf{1 3 b}$

All hydrogen atoms and the hydroxy group occupy an axial position, while the remaining substituents are in equatorial positions. This is consistent with the ${ }^{1} \mathrm{H}$ NMR data for other similar tetrahydropyranols $\mathbf{1 3 b}-\mathbf{f}$, therefore, their configuration was assumed by analogy.
Dehydration of compound $\mathbf{1 3 b}$ in the presence of $p$-toluenesulfonic acid gives dihydropyran $\mathbf{1 4}$ as a single stereoisomer (Scheme 4).

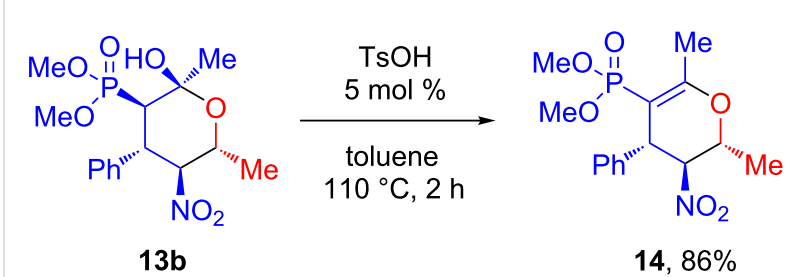

Scheme 4: Synthesis of (3,4-dihydro-2H-pyran-5-yl)phosphonate 14.

\section{Conclusion}

In summary, a convenient protocol for the synthesis of phosphoryl-substituted pyrrolidines with three contiguous stereocenters via asymmetric addition of $\beta$-keto phosphonates to nitroolefins and subsequent reductive cyclization of enantioenriched, diastereomerically pure Michael adducts was developed. The present study also demonstrates that the diastereoselective cascade Henry/acetalyzation reaction with keto nitro phosphonates and aldehydes leading to tetrahydropyranylphosphonates can be efficiently performed within an aqueousorganic medium with $\mathrm{K}_{2} \mathrm{CO}_{3}$ /TEBAC as the catalyst, and the corresponding products can be obtained with high diastereo- 
meric purity. These methods enable the formation of highly enantioenriched phosphoryl-substituted heterocycles from readily available $\beta$-keto phosphonates using an inexpensive $\mathrm{Ni}(\mathrm{II})$ complex as the catalyst in the key step.

\section{Supporting Information}

\section{Supporting Information File 1}

Experimental procedures, copies of NMR, FTIR, and mass spectra, HPLC and X-ray diffraction data.

[https://www.beilstein-journals.org/bjoc/content/ supplementary/1860-5397-16-174-S1.pdf]

\section{Supporting Information File 2}

Crystallographic information files (CIF). [https://www.beilstein-journals.org/bjoc/content/ supplementary/1860-5397-16-174-S2.zip]

\section{Funding}

The authors gratefully acknowledge the support of this work by the Russian Science Foundation (project 18-13-00447). Spectral and chromatographic analysis was performed by joint use center «Research of physical and chemical properties of substances and materials» with financial support of the Russian Ministry of Science and Higher Education for a basic part of a research project 0778-2020-0005. The X-ray studies were performed in the frame of the development program of the Moscow State University.

\section{ORCID ${ }^{\circledR} \mathrm{iDs}$}

Alexander N. Reznikov - https://orcid.org/0000-0002-6056-6415 Dmitry S. Nikerov - https://orcid.org/0000-0002-1603-6185 Anastasiya E. Sibiryakova - https://orcid.org/0000-0001-5005-1373 Victor B. Rybakov - https://orcid.org/0000-0002-6720-0619 Evgeniy V. Golovin - https://orcid.org/0000-0003-4008-8433 Yuri N. Klimochkin - https://orcid.org/0000-0002-7335-4040

\section{References}

1. Horsman, G. P.; Zechel, D. L. Chem. Rev. 2017, 117, 5704-5783. doi:10.1021/acs.chemrev.6b00536

2. Mucha, A.; Kafarski, P.; Berlicki, Ł. J. Med. Chem. 2011, 54 , 5955-5980. doi:10.1021/jm200587f

3. Chen, L.; Liu, X.-Y.; Zou, Y.-X. Adv. Synth. Catal. 2020, 362, 1724-1818. doi:10.1002/adsc.201901540

4. Moonen, K.; Laureyn, I.; Stevens, C. V. Chem. Rev. 2004, 104, 6177-6216. doi:10.1021/cr030451c

5. Hanaya, T.; Itoh, C. Heterocycles 2011, 82, 1675-1683. doi:10.3987/com-10-s(e)80
6. Belyaev, A.; Zhang, X.; Augustyns, K.; Lambeir, A.-M.; De Meester, I.; Vedernikova, I.; Scharpé, S.; Haemers, A. J. Med. Chem. 1999, 42, 1041-1052. doi:10.1021/jm981033g

7. Boduszek, B.; Oleksyszyn, J.; Kam, C.-M.; Selzler, J.; Smith, R. E.; Powers, J. C. J. Med. Chem. 1994, 37, 3969-3976. doi:10.1021/jm00049a016

8. Shie, J.-J.; Fang, J.-M.; Lai, P.-T.; Wen, W.-H.; Wang, S.-Y.; Cheng, Y.-S. E.; Tsai, K.-C.; Yang, A.-S.; Wong, C.-H. J. Am. Chem. Soc. 2011, 133, 17959-17965. doi:10.1021/ja207892q

9. Wallimann, K.; Vasella, A. Helv. Chim. Acta 1990, 73, 1359-1372. doi:10.1002/hlca.19900730523

10. Viveros-Ceballos, J. L.; Martínez-Toto, E. I.; Eustaquio-Armenta, C.; Cativiela, C.; Ordóñez, M. Eur. J. Org. Chem. 2017, 6781-6787. doi:10.1002/ejoc.201701330

11. Ordóñez, M.; Arizpe, A.; Sayago, F. J.; Jiménez, A. I.; Cativiela, C. Molecules 2016, 21, 1140. doi:10.3390/molecules21091140

12. Viveros-Ceballos, J. L.; Ordóñez, M.; Sayago, F. J.; Jiménez, A. I.; Cativiela, C. Eur. J. Org. Chem. 2016, 2711-2719. doi:10.1002/ejoc.201600313

13. Viveros-Ceballos, J. L.; Sayago, F. J.; Cativiela, C.; Ordóñez, M. Eur. J. Org. Chem. 2015, 1084-1091. doi:10.1002/ejoc.201403418

14. Bonilla-Landa, I.; Viveros-Ceballos, J. L.; Ordóñez, M. Tetrahedron: Asymmetry 2014, 25, 485-487. doi:10.1016/j.tetasy.2014.02.014

15. Viveros-Ceballos, J. L.; Cativiela, C.; Ordóñez, M. Tetrahedron: Asymmetry 2011, 22, 1479-1484. doi:10.1016/j.tetasy.2011.08.003

16. Hirata, S.; Kuriyama, M.; Onomura, O. Tetrahedron 2011, 67 , 9411-9416. doi:10.1016/j.tet.2011.09.080

17. Kaboudin, B.; Kato, J.-y.; Aoyama, H.; Yokomatsu, T. Tetrahedron: Asymmetry 2013, 24, 1562-1566. doi:10.1016/j.tetasy.2013.10.013

18. Amedjkouh, M.; Westerlund, K. Tetrahedron Lett. 2004, 45, 5175-5177. doi:10.1016/j.tetlet.2004.04.009

19. Kaname, M.; Arakawa, Y.; Yoshifuji, S. Tetrahedron Lett. 2001, 42 , 2713-2716. doi:10.1016/s0040-4039(01)00283-0

20. Markitanov, Y. N.; Timoshenko, V. M.; Shermolovich, Y. G.; Mykhalchuk, V. L.; Grafova, I. A.; Grafov, A. V. Chem. Heterocycl. Compd. 2016, 52, 503-506. doi:10.1007/s10593-016-1916-5

21. Yan, L.; Hale, J. J.; Lynch, C. L.; Budhu, R.; Gentry, A.; Mills, S. G.; Hajdu, R.; Keohane, C. A.; Rosenbach, M. J.; Milligan, J. A.; Shei, G.-J.; Chrebet, G.; Bergstrom, J.; Card, D.; Rosen, H.; Mandala, S. M. Bioorg. Med. Chem. Lett. 2004, 14, 4861-4866. doi:10.1016/j.bmcl.2004.07.049

22. Paulsen, H.; Greve, W. Chem. Ber. 1973, 106, 2114-2123. doi:10.1002/cber.19731060705

23. Zheng, K.; Liu, X.; Feng, X. Chem. Rev. 2018, 118, 7586-7656. doi:10.1021/acs.chemrev.7b00692

24. Reznikov, A. N.; Klimochkin, Y. N. Synthesis 2020, 52, 781-795. doi:10.1055/s-0039-1690044

25. Pellissier, H. Adv. Synth. Catal. 2015, 357, 2745-2780. doi:10.1002/adsc.201500512

26. Mauduit, M.; Baslé, O.; Clavier, H.; Crévisy, C.; Denicourt-Nowicki, A. Metal-Catalyzed Asymmetric Nucleophilic Addition to Electron-Deficient Alkenes. In Comprehensive Organic Synthesis II, 2nd ed.; Knochel, P.; Molander, G. A., Eds.; Elsevier: Oxford, U.K., 2014; Vol. 4, pp 189-341. doi:10.1016/b978-0-08-097742-3.00406-7

27. Pellissier, H. Curr. Org. Chem. 2018, 22, 323-344. doi:10.2174/1385272821666170818160915 
28. Maria Faísca Phillips, A. Curr. Org. Synth. 2016, 13, 687-725. doi:10.2174/1570179412666150914200843

29. Heravi, M. M.; Hajiabbasi, P.; Hamidi, H. Curr. Org. Chem. 2014, 18, 489-511. doi:10.2174/13852728113176660149

30. Somanathan, R.; Chavez, D.; Servin, F. A.; Romero, J. A.; Navarrete, A.; Parra-Hake, M.; Aguirre, G.; Anaya de Parrodi, C.; Gonzalez, J. Curr. Org. Chem. 2012, 16, 2440-2461. doi:10.2174/138527212803520128

31. Zhang, Y.; Wang, W. Catal. Sci. Technol. 2012, 2, 42-53. doi:10.1039/c1cy00334h

32. Almaşi, D.; Alonso, D. A.; Nájera, C. Tetrahedron: Asymmetry 2007, 18, 299-365. doi:10.1016/j.tetasy.2007.01.023

33. Pellissier, H. Adv. Synth. Catal. 2016, 358, 2194-2259. doi:10.1002/adsc.201600462

34. Bugaut, X.; Bonne, D.; Coquerel, Y.; Rodriguez, J.; Constantieux, T. Curr. Org. Chem. 2013, 17, 1920-1928. doi:10.2174/13852728113179990090

35. Gasperi, T.; Miceli, M.; Campagne, J.-M.; Marcia de Figueiredo, R. Molecules 2017, 22, 1636. doi:10.3390/molecules22101636

36. Lu, L.-Q.; Chen, J.-R.; Xiao, W.-J. Acc. Chem. Res. 2012, 45 , 1278-1293. doi:10.1021/ar200338s

37. Urbanietz, G.; Atodiresei, I.; Enders, D. Synthesis 2014, 46, 1261-1269. doi:10.1055/s-0033-1340826

38. Mondal, B.; Pan, S. C. Synlett 2018, 29, 576-580. doi:10.1055/s-0036-1591736

39. Corbett, M. T.; Xu, Q.; Johnson, J. S. Org. Lett. 2014, 16, 2362-2365. doi:10.1021/ol500679w

40. Guo, S.; Xie, Y.; Hu, X.; Huang, H. Org. Lett. 2011, 13, 5596-5599. doi:10.1021/ol2023196

41. Nakamura, A.; Lectard, S.; Hashizume, D.; Hamashima, Y.; Sodeoka, M. J. Am. Chem. Soc. 2010, 132, 4036-4037. doi:10.1021/ja909457b

42. Ma, H.; Liu, K.; Zhang, F.-G.; Zhu, C.-L.; Nie, J.; Ma, J.-A. J. Org. Chem. 2010, 75, 1402-1409. doi:10.1021/jo901991v

43. Xu, Y.; Matsunaga, S.; Shibasaki, M. Org. Lett. 2010, 12, 3246-3249. doi:10.1021/ol101185p

44. Barnes, D. M.; Ji, J.; Fickes, M. G.; Fitzgerald, M. A.; King, S. A.; Morton, H. E.; Plagge, F. A.; Preskill, M.; Wagaw, S. H.; Wittenberger, S. J.; Zhang, J. J. Am. Chem. Soc. 2002, 124, 13097-13105. doi:10.1021/ja026788y

45. Reznikov, A. N.; Sibiryakova, A. E.; Rybakov, V. B.; Klimochkin, Y. N Tetrahedron: Asymmetry 2015, 26, 1050-1057.

doi:10.1016/j.tetasy.2015.08.003

46. Reznikov, A. N.; Sibiryakova, A. E.; Klimochkin, Y. N. Russ. J. Gen. Chem. 2014, 84, 2280-2282. doi:10.1134/s1070363214110437

47. Budzisz, E.; Pastuszko, S. Tetrahedron 1999, 55, 4815-4824. doi:10.1016/s0040-4020(99)00153-2

48. Gray, M. D. M.; Smith, D. J. H. Tetrahedron Lett. 1980, 21, 859-860. doi:10.1016/s0040-4039(00)71526-7

49. Vassileva, V.; Georgiev, E. M.; Troev, K.; Roundhill, D. M. Phosphorus, Sulfur Silicon Relat. Elem. 1994, 92, 101-107. doi:10.1080/10426509408021462

50. Reznikov, A. N.; Nikerov, D. S.; Sibiryakova, A. E.; Rybakov, V. B.; Golovin, E. V.; Klimochkin, Yu. N. CCDC 1919294: Experimental Crystal Structure Determination, 2020. doi:10.5517/ccdc.csd.cc22f5qf

51. Reznikov, A. N.; Nikerov, D. S.; Sibiryakova, A. E.; Rybakov, V. B.; Golovin, E. V.; Klimochkin, Yu. N. CCDC 1846644: Experimental Crystal Structure Determination, 2018. doi:10.5517/ccdc.csd.cc1zzl5q

\section{License and Terms}

This is an Open Access article under the terms of the Creative Commons Attribution License (https://creativecommons.org/licenses/by/4.0). Please note that the reuse, redistribution and reproduction in particular requires that the authors and source are credited.

The license is subject to the Beilstein Journal of Organic Chemistry terms and conditions: (https://www.beilstein-journals.org/bjoc)

The definitive version of this article is the electronic one which can be found at: https://doi.org/10.3762/bjoc.16.174 